\title{
Vibrational Microfeeding of Polymer and Metal Powders for Locally Graded Properties in Powder-Based Additive Manufacturing
}

\author{
R. Rothfelder (D), L. Lanzl, J. Selzam, D. Drummer, and M. Schmidt
}

Submitted: 18 December 2020 / Revised: 8 September 2021 / Accepted: 11 September 2021 / Published online: 12 October 2021

\begin{abstract}
Subject of this work is the contact mechanical properties and flowability of polymer and metal powders when they are dispensed on the surface of a powder bed for use in laser-based powder bed fusion in additive manufacturing. Generating local part properties in metal as well as polymer-based powder bed fusion processes is of high interest, so an approach is made to locally add additives by a vibrational microfeeding system for metal and polymer powders. To realize a controlled powder discharge, the behavior of additives, which are dropped on a surface and on a powder bed is analyzed. Influencing factors for mass flow of the powders will be excitation frequency, excitation amplitude and capillary diameter on the side of experimental setup as well as particle size distribution and physical properties on the material side.
\end{abstract}

Keywords additive manufacturing, in situ alloying, polymers and plastics, powder metallurgy, powder bed fusion, titanium

\section{Introduction}

Additive manufacturing (AM) and especially the laser-based powder bed fusion of metals and polymers (PBF-LB/M/P) have been (Ref 1) and are to the day subject of extensive investigations (Ref 2). PBF-LB-M/P is a manufacturing process, which builds up parts from powder via melting the material through a laser beam $(\operatorname{Ref} 3)$. The core of the process is identical for polymers and metals. A vertically adjustable platform is moved downwards into a cavity and both, the lowered platform and the cavity form the powder bed. A thin powder layer is applied at the work area, while a coater transports powder from a feedstock system to the platform (Ref 4), p. 1918]. The laser scans the first layer, which is a slice of the part

This invited article is part of a special topical focus in the Journal of Materials Engineering and Performance on Additive Manufacturing. The issue was organized by Dr. William Frazier, Pilgrim Consulting, LLC; Mr. Rick Russell, NASA; Dr. Yan Lu, NIST; Dr. Brandon D. Ribic, America Makes; and Caroline Vail, NSWC Carderock.

R. Rothfelder and M. Schmidt, Institute of Photonic Technologies, Friedrich-Alexander-Universität (FAU) Erlangen-Nürnberg, Erlangen, Germany; Collaborative Research Center 814-Additive Manufacturing, Friedrich-Alexander-Universität (FAU) Erlangen-Nürnberg, Erlangen, Germany; and Erlangen Graduate School in Advanced Optical Technologies (SAOT), Friedrich-Alexander Universität ErlangenNürnberg, 91052 Erlangen, Germany; L. Lanzl and D. Drummer, Collaborative Research Center 814-Additive Manufacturing, FriedrichAlexander-Universität (FAU) Erlangen-Nürnberg, Erlangen, Germany; and Institute of Polymer Technology, Friedrich-Alexander-Universität (FAU) Erlangen-Nürnberg, Erlangen, Germany; and J. Selzam, Friedrich-Alexander-Universität (FAU) Erlangen-Nürnberg, Erlangen, Germany. Contact e-mail: richard.rothfelder@lpt.uni-erlangen.de. to be build and melts the powder following defined trajectories. The welding beads created by the laser from the solidified layer. The platform is lowered by a defined space, which defines the layer height and the laser scans the next cross section. These steps are repeated until the part is finished. This manufacturing technology has advantages over conventional manufacturing techniques like the production of high-resolution features with high design flexibility combined with a reduction of material waste and the possibility to create internal passages (Ref 4), p. 1919].

Nevertheless, only global material properties can be generated. Locally defined material or part properties within one process have not been feasible so far. One approach is the in situ modification of the materials and the adjustment of local part properties, thus leading to graded part properties, see Fig. 1. To perform the in situ modification, a system, which transports quantities in the milligram range of the chosen additive material to the process zone, is needed. The present work shows a vibration-based micropowder feeding system to adapt the local properties and composition of powders and therefore of produced parts. Possible industrial applications would be the improvement in formability of metal-sheetforming/additive manufacturing or more flexibility in the construction of compliant mechanisms considering metal applications. For polymer applications, generating parts with graded properties regarding rigidity and strength for gripper applications is a use case. This approach is the topic of recent research in the Collaborative Research Centre 814 (CRC 814) Additive Manufacturing at the FAU Erlangen-Nürnberg. In contrast to direct energy deposition (DED-LB), it is difficult to mix additives in the feedstock powder without changing the material properties of the whole powder stock, since PBF-LB machines only use a single powder container, which feeds powder in the process zone. DED-LB machines can use multiple powder feeders, where powders ultimately are mixed in the powder stream. In PBF-LB machines, the additives are dispersed in the base material during the process. A local change of mechanical properties or the chemical composition of the powder and therefore for the part is not possible in one 


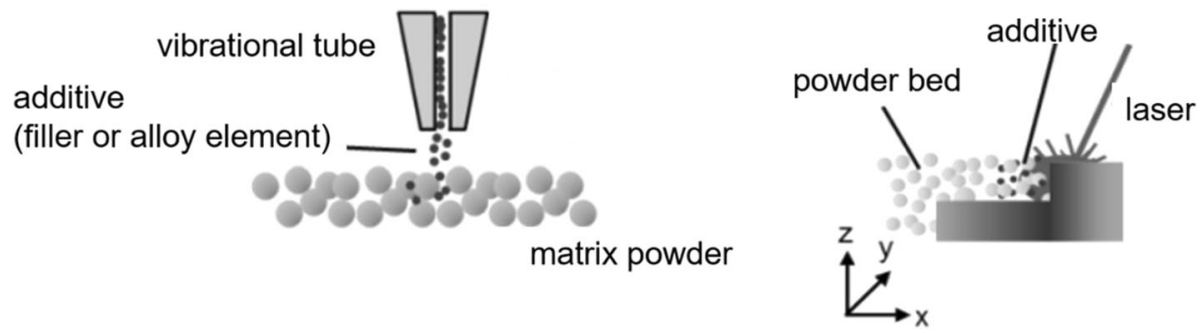

Fig. 1 Strategy for local dispensing of additives into the powder bed during PBF

single layer within the recent state of the art. To proof the featured concept for PBF-LB/P/M, several polymer and metal powders are characterized concerning their mass flow and geometrical distribution after dispensing. There are several factors which have impact on flowability of powder materials (Ref 5), p. 242]. This work will primarily focus on the generated mass flow. The investigated materials are polymers (PA12, PA12 mixed with glass fibers) and metals (Ti6Al4V, Cu, $\mathrm{Fe}, \mathrm{V})$. The goal of this work is to find transferable knowledge for both material systems to define guidelines for the local manipulation of chemical composition, thus providing the opportunity for creating graded structures in powder bed-based AM processes. The experiments will be conducted on a selfdeveloped experimental setup, which will perspectively be implemented in a PBF-LB-machine.

For a local powder discharge, it is necessary to generate a controlled powder flow of the additives with a start-stop-effect, so that only powder discharge takes place when the tube is excitated. Basic parameters like excitation frequency and tube diameter and their corresponding effect on the mass flow and geometry of the dispended powder line are analyzed. The results, like mass flow and geometry of the dispensed additives, are necessary to derive process strategies for local powder dispensing as parameters like lateral discharge velocity to fulfill requirements regarding process stability and concentration of the additives.

\section{State of the Art}

\subsection{POWDER-BASED AM and In Situ Feedstock Modification}

There have been many approaches to use in situ modification within additive manufacturing technologies to produce parts with customized properties. Using DED the system engineering itself provides the possibility to add particles to tailor the alloy during the process itself (Ref 6). This has been investigated, for example, for tool steels with the addition of carbon black (Ref 7). In PBF-LB, however, this is linked with more effort on the process side. There are two main possibilities for in situ modification. The first one is the mixing of the whole powder feed stock with additives like nanoparticles (e.g., carbon black, SiOx) (Ref 8, 9), mixing of different elemental powders or pre-alloyed powders of similar particle size distribution (Ref 10) and copper or filler materials like glass fibers (Ref 11). A big issue is the powder spreading of binary powder systems during PBF-LB, which has fundamentally been analyzed by Chen et al. (Ref 12,13$)$ as well as its effect on the orientation of fillers (Ref 14, 15). The second one is to alter the composition of the material in the powder bed itself. This can go as far as combining two different materials and has been topic to research for polymers (Ref 16) as well as for metals (Ref 17, 18). The modification of the basic powder material is a potent lever for AM. Within the CRC 814, the approach of local in situ modification is followed ( $\operatorname{Ref} 19$ ). The idea is to dispense small amounts of powders to vary the chemical composition of the base powder, but only locally on the area, which is scanned by the laser. This could be used in several industrial applications and allows for new degrees of freedom in designing AM-forming hybrid parts, but is linked to several challenges. Contamination of the base powder stock through sparks and drifting caused by the inert gas flow has to be prevented. The mass flow must be controlled precisely to reach a specified ratio of base and additive material.

\subsection{PBF-LB/M of Ti6Al4 and PBF-LB/P of Filled PA 12}

PBF of Ti6AL4V has been topic to intensive research and is also well understood today (Ref 20, 21-23) Klicken oder tippen Sie hier, um Text einzugeben. Process parameters for nearly fully dense parts are provided by companies selling commercial industrial $\mathrm{PBF}-\mathrm{LB} / \mathrm{EB} / \mathrm{M}$ machines. Ti6Al4V parts produced by means of PBF-LB/M are already used in different industries. Examples are medical implants due to its biocompatibility or high-performance parts for aerospace or chemical applications (Ref 24, 25). Current research concerning the titanium alloy focuses on the fatigue strength (Ref 26, 27) and the process combination of sheet metal forming and additive manufacturing. The forming operations of complex Ti6Al4V parts are challenging, because the titanium $\alpha$-phase is hard and brittle compared to $\beta$-titanium. So it would be of advantage to locally stabilize the $\beta$-phase in the areas of the part which will be deformed during the forming operation to extend the possibilities of subsequent forming operations (Ref 28).

The process of powder bed fusion for polymers is similar to the metal process. Polyamide 12 is the standard material for $\mathrm{PBF} / \mathrm{P}$ and is the most used polymer powder for this case. As it offers best processing behavior, it is used as matrix material in this study to understand occurring effects by local filler discharging. PA 12 has still a market share of over $90 \%$ leading to a low variety of part properties for PBF/P-parts (Ref 2 ). Using fillers, tailored part properties can be set by the variation of the filler content, shape, material and particle size distribution. Exemplarily, glass fillers are mainly used to increase stiffness, which is interesting for housing applications in automotive (Ref 30). Metal fillers, like aluminum or copper, induce improved machinability (Ref 31 ) or heat conductivity (Ref 11). Nevertheless, these part properties can only be set globally so far. 
For PBF-LB, there are two main systems for applying powder to the scanning area. One is a system of two powder reservoirs, where one contains the feedstock and one is the actual powder bed, shown in Fig. 2. The reservoir with the feedstock is elevated, so the coater can move the elevated powder over the actual building plate (Ref 8$)$. The other one is a moving coater which is filled with powder from a separated feedstock, which covers and coats the powder bed in one step (Ref 32). For local dispensing different materials, a modification of existing set-ups is normally necessary.

The PBF-LB process for polymers has the same principles, and the process sequence is analogous to the metal process.

\section{Materials}

\subsection{Matrix Materials (REM Camsizer)}

The metal matrix material is Ti6Al4V, which is an $\alpha+\beta$ titanium alloy. The $\alpha$-phase of titanium is only barely suited for subsequent forming operations. Stabilizing the better formable $\beta$-phase during solidification in designated parts of the workpiece could be of advantage for further processing steps of the produced part. The matrix material for the polymer-based filled systems is polyamide 12 (PA 12). A Morphologi G3 (Malvern Instruments, UK) camsizer was used to determine the particle size distribution of the used Ti6Al4V powder and PA 12, which is shown in Table 1. The Morphologi G3 uses laser diffraction method for calculating the particle diameter.

\subsection{Alloying Elements/Fillers}

The metal powders copper, iron and vanadium are chosen because of their capability of stabilizing the titanium $\beta$-phase during solidification (Ref 19). Short glass fibers for polymer processes lead to an increased stiffness (Ref 33$)$. The data of the additives are depicted in Table 2 .

\section{Experimental Setup}

The experimental setup for this work consists of three main parts, which are decisive for the outcome. These parts are a piezo actuator, a linear servo motor and a glass dispensing tube. The tube is filled with additional alloying material for the metal powders and the fillers for the polymer powders. The used glass dispenser tubes are made by Hilgenberg $\mathrm{GmbH}$ (Germany). Figure 3 shows an example of one used glass dispenser tube. The tube is connected to the piezo actuator, which is linked to the linear motor for a horizontal movement for deploying lines of powder, as shown in Fig. 3.

The mass flow from the tube is realized via vibration from the actuator. Without vibration, the flow is interrupted, thus creating a start-stop-function. The powder mass flow is interrupted by bridges, which build up at conical cross sections of the tubes as result of wedging of the particles. This is a common problem in bulk solid technology, but in this context, the phenomenon can be used for process control and is shown in Fig. 4b. In the case of fine-grained, cohesive bulk solids, like the used powder materials, the bridging is caused by the compressive strength based on the adhesive forces between the powder particles. This is called bulk strength (Ref 34). This corresponds to the information from the literature (Ref 35), p. 144]. The decision which mass flow values are used in the further experiments is dependent on several aspects. The ratio from the dispensed mass and the standard deviation should be maximal to achieve a high precision concerning applied mass and geometrical accuracy of the powder lines. Another issue is the absolute amount of mass applied. Being able to vary the mass flow from low quantities to high quantities is needed to change the proportion of alloy elements/fillers (Fig. 4).

\subsection{Piezo Actuator and Amplifier}

The used actuator is a multilayer piezo actuator PSt 1000/ $16 / 20 \mathrm{VS} 25$, and the amplifier is a LE 1000/035 one-channelamplifier, both by Piezosystem Jena GmbH (Germany). While the actuator can generate frequencies up to $15 \mathrm{kHz}$ with an amplitude of $10 \mathrm{~V}$, the amplifier is designed for a voltage of up to $1000 \mathrm{~V}$.

Table 3 depicts the used vibration parameters for the powder discharge experiments. The frequency ranges were chosen depending on the powder flow behavior of the selected materials.

In a first step, the powder mass flow is characterized dependent on the excitation frequency, the excitation amplitude and the diameter of the dispensing tube. This characterization and therefore the choice of values for the tests were chosen by a qualitative review for the mass flow stability. The best results out of the vibrational mass flow experiments were then used for geometrical characterization of the discharged powder.

\subsection{Mass Flow Characterization}

The mass flow characterization was conducted via weighing tests using a precision balance XS205DU (Mettler Toledo, Switzerland) with a weighing precision of $\pm 0,1 \mathrm{mg}$. To avoid contamination of the balance with powder particles differential weighing was used. Glass containers were weighed to determine their mass and were then filled with powder from the

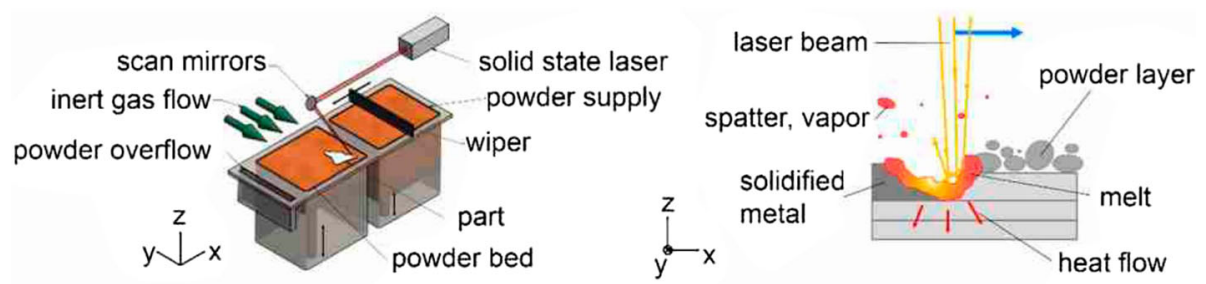

(a)

(b)

Fig. 2 Laser-based powder bed fusion fundamentals: basic layout of a PBF-LB machine (Ref 29) 
Table 1 Particle size distribution and particle shapes of the matrix materials

\begin{tabular}{|c|c|c|c|c|c|}
\hline Process & Matrix material & Powder type & Supplier & ${ }^{D_{10}} \mathbf{3}^{/ D_{50}} \mathbf{3}^{/ D_{90,3}}(\mu \mathrm{m})$ & Particle shape \\
\hline PBF- LB/M & Metal & Ti6Al4V & $\begin{array}{l}\mathrm{AP}+\mathrm{C} \\
\text { (Canada) }\end{array}$ & $10 / 34 / 60 \mu \mathrm{m}$ & Spherical \\
\hline PBF-LB/P & Polymer & PA 12 (PA2200) & $\begin{array}{l}\text { EOS GmbH } \\
\text { (Germany) }\end{array}$ & $46 / 61 / 83 \mu \mathrm{m}$ & Potato-like \\
\hline
\end{tabular}

Table 2 Particle size distribution of the used metal powders and fillers

\begin{tabular}{|c|c|c|c|c|c|}
\hline Process & Additive material & Supplier & $\begin{array}{l}\text { Powder } \\
\text { generation } \\
\text { method }\end{array}$ & $\begin{array}{c}\text { Particle size } \\
\text { distribution }^{D} \mathbf{1 0 , 3 ^ { / D }} \mathbf{5 0 , 3}^{\prime} \\
{ }_{\mathbf{D}}^{\mathbf{9 0 , 3}(\mu \mathrm{m}) \mathrm{s}}\end{array}$ & $\begin{array}{c}\text { Particle } \\
\text { shape }\end{array}$ \\
\hline \multirow[t]{3}{*}{$\begin{array}{l}\text { Additives for } \\
\text { PBF- LB/M }\end{array}$} & Copper & $\begin{array}{l}\text { Ecka } \\
\text { Granules (Germany }\end{array}$ & Argon-jetted & $7 / 13 / 20 \mu \mathrm{m}$ & Spherical \\
\hline & Iron & $\begin{array}{l}\text { PMCtec } \\
\text { (Germany) }\end{array}$ & Water jetted & $20 / 39 / 56 \mu \mathrm{m}$ & Spattered \\
\hline & Vanadium & $\begin{array}{l}\text { NMD New } \\
\text { Materials Development } \\
\text { GmbH (Germany) }\end{array}$ & Grinded & $10 / 34 / 60 \mu \mathrm{m}$ & Spattered \\
\hline Filler for PBF- LB/P & $\begin{array}{l}\text { Short glass fibers (premixed } \\
\text { with PA } 12 \text { with a filler grade } \\
\text { of } 5 \text { and } 20 \text { vol. } \% \text { ) }\end{array}$ & Taishin Fiberglass (China) & Milled & $\begin{array}{l}24 / 51 / 112 \mu \mathrm{m} \\
\mathrm{L} / \mathrm{D}=5\end{array}$ & Fibers/rods \\
\hline
\end{tabular}

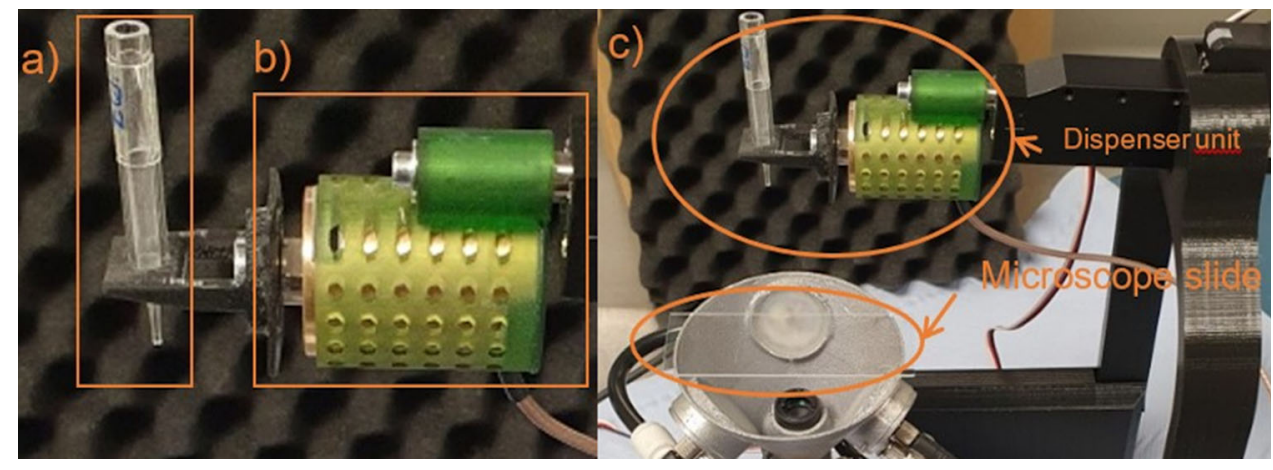

Fig. 3 Experimental setup (a) glass dispenser tube (b) piezo actuator in contraption and (c) the whole contraption

tubes over a determined time to reduce systematical weighing error, altering frequency and amplitude of the actuator and the opening diameter of the dispensing tubes. The filled container is again weighed to determine the applied mass. Every configuration was repeated three times for estimation of standard deviation. The applied mass divided by the time the actuator applies excitation on the tube gives the mean powder mass flow per second dependent on frequency, amplitude and opening diameter. To quantify the influence of the given parameter, a design of experiments (DoE) was used. The mean mass flow per second is a calculated parameter that is used for calculating the impact of frequency, amplitude and opening diameter on mass output of the dispensing system with processrelated conditions.

\subsection{Geometrical Characterization}

The geometrical characterization of the applied powder lines was investigated by means of optical microscopy. A scheme of the setup is shown in Fig. 5. A distance of $1 \mathrm{~mm}$ from the microscope slides is used for the deposition of the lines. To be as close as possible to realistic process, the dispensing unit was moved. For the optical investigation of the lines, an USB microscope (digimicro 2.0, PCE-instruments, Germany) was used. The recorded images were taken with a benchmark for scale on them. Afterward, the program gimp 2.99.2 (GNU Image Manipulation Program, open source software) was used to measure the scale of the powder lines, by scaling the pictures pixel/length unit to the benchmark on the picture. Gauge blocks were used to guarantee the exact height ratio toward the level of the powder line.

\subsection{Powder Bed Interaction of Dispensed Powder}

The interaction of the dispensed powder with a powder bed was also characterized using optical microscopy. Instead of applying a line on a microscope slide, the powder is applied to a powder bed surrogate. Therefore, a polymer foil attached to a 
framework is coated with the corresponding matrix material for easy displacement of the contaminated powder. The matrix material is distributed by low frequent vibration applied

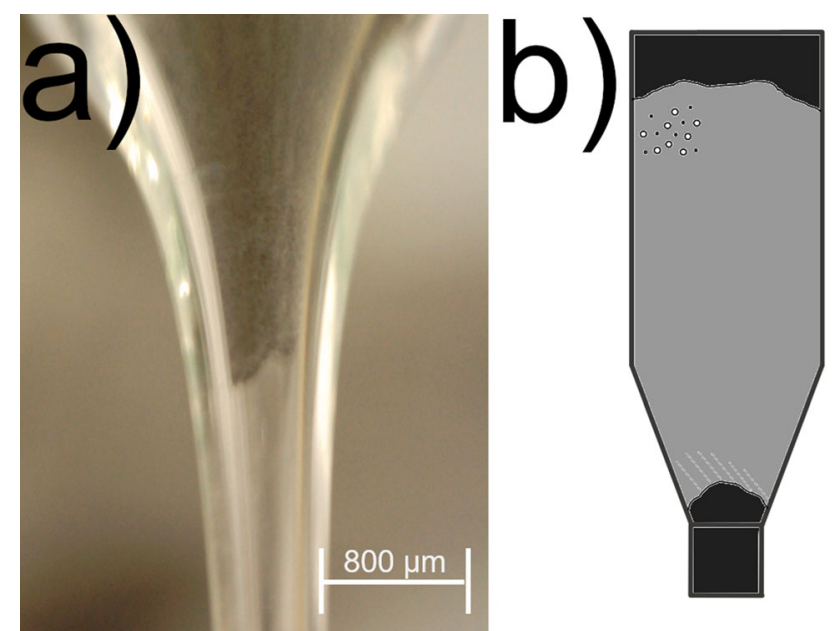

Fig. 4 (a) Conical cross section interrupting the powder flow without vibration, (b) schematic cross section of bridging in the hopper due to compressive strength of the powder manually and raked with a squeegee. A scheme of the process is shown in Fig. 6. The contaminated powder is the feedstock material mixed with the additives. A separation of the feedstock material and the additives afterward is linked with great effort and therefore not of interest in this context since it should be as material efficient as possible. Selected configurations of the powder lines are applied on the powder surface. The distance between tube opening and surface is $1 \mathrm{~mm}$. The mass of the matrix material deposited in the surrogate is held constant to achieve good repeatability and comparability.

\section{Results and Discussion}

\subsection{Mass Flow Characterization of Metal Powders}

The powder mass flow for the three different elemental metal powders $\mathrm{Fe}, \mathrm{Cu}, \mathrm{V}$ was analyzed. The configuration shown in Fig. 7a uses frequencies in the range from $1500 \mathrm{~Hz}$ up to $1900 \mathrm{~Hz}$, in $100 \mathrm{~Hz}$ steps at an amplitude of $10 \mathrm{~V}$. For this configuration, the only used tube diameter for copper powder is $110 \mu \mathrm{m}$ since bigger diameters cause an uncontrolled powder flow. For a frequency of $1.5 \mathrm{kHz}$, the mass flow is significantly lower than for the other values. The maximum calculated mass

Table 3 Used vibrational parameters and glass tube diameters for the metal and polymer PBF-LB-process

\begin{tabular}{|c|c|c|c|}
\hline & Amplitude & Frequency range & Glass tube opening diameter \\
\hline PBF-LB/M & $\begin{array}{c}5 \mathrm{~V} \text { (vanadium) } \\
10 \mathrm{~V} \text { (copper, iron) }\end{array}$ & $1000-3000 \mathrm{~Hz}$ & $110 / 530 / 630 \mu \mathrm{m}$ \\
\hline PBF-LB/P & $5 \mathrm{~V}$ & $300-800 \mathrm{~Hz}$ & $500 / 700 / 1000 \mu \mathrm{m}$ \\
\hline
\end{tabular}

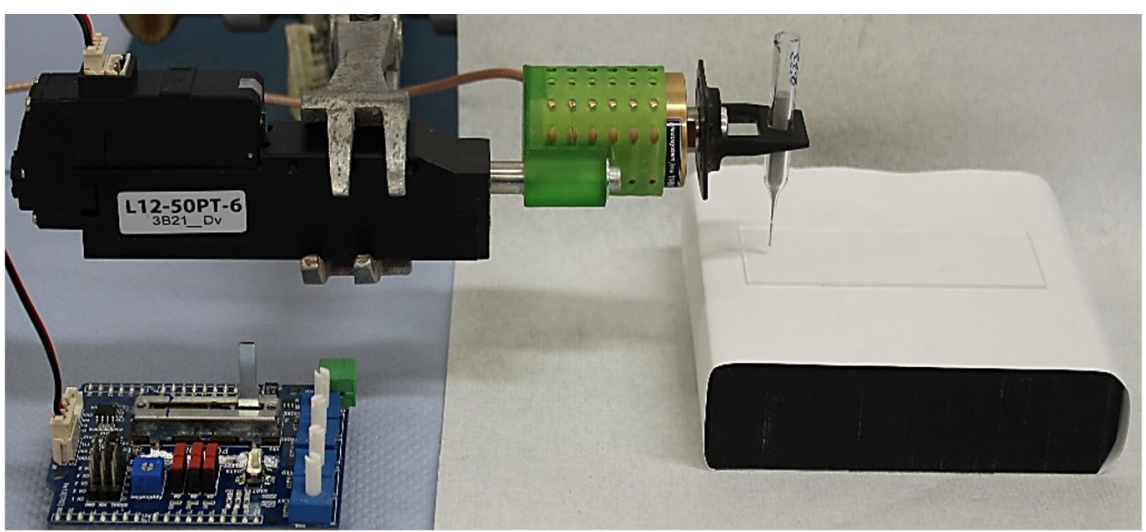

Oszilloscopefrequenz

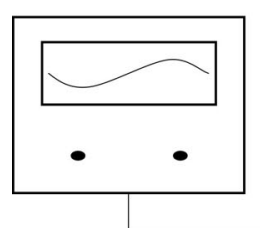

Frequency generator

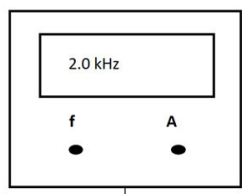

Signal amplifier

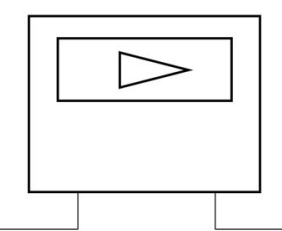

USB-Camera

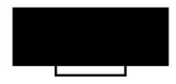

Piezo element actuator

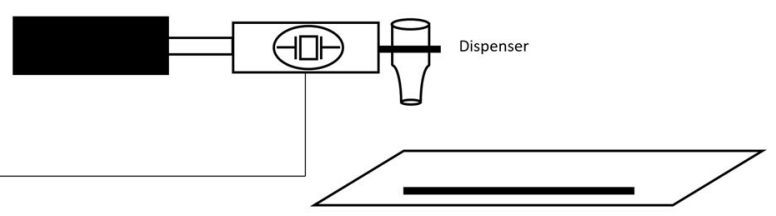

Object slide with positioned standard

Fig. 5 Experimental setup for geometrical powder line characterization 


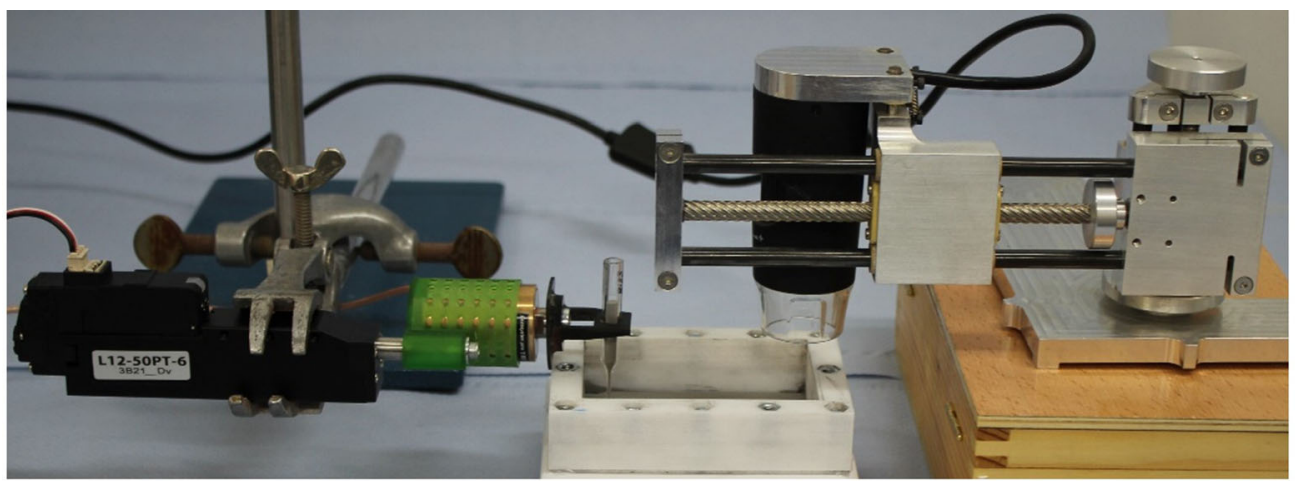

USB-Camera

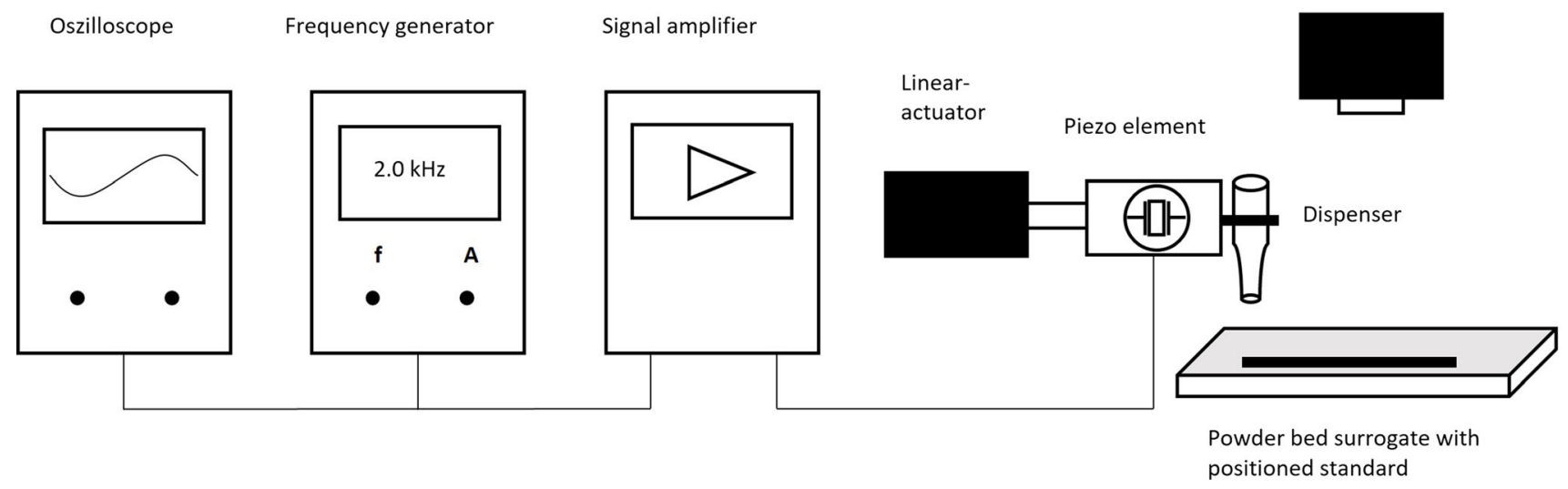

Fig. 6 Experimental setup for powder line powder bed interaction tests
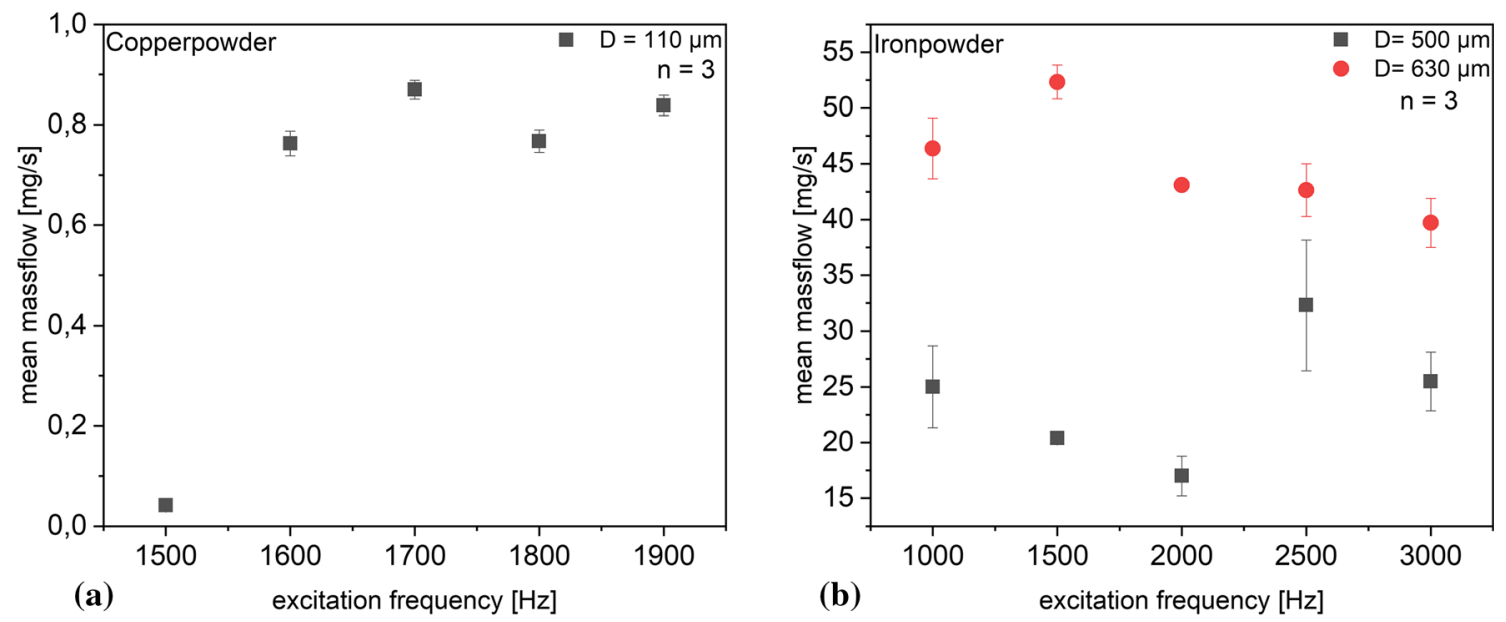

Fig. 7 Conveyor curve of (a) copper powder with amplitude $=10 \mathrm{~V}$ and a dispenser opening diameter of $110 \mu \mathrm{m}$ and (b) iron powder with amplitude $=10 \mathrm{~V}$ and a dispenser opening diameter of $500 \mu \mathrm{m}$ and $630 \mu \mathrm{m}$

flow is $0.87 \mathrm{mg} / \mathrm{s}$. After a strong increase in mass flow, the results alternately rise and fall with each step. This trend was also observed in the other configurations. A possible explanation is the resonance frequency of the setup. Specific frequencies can be closer to higher modes of the resonant frequency and therefore increase the excitation, leading to a higher mass flow.

The conveyor curve of iron powder (also shown in Fig. 7b) ranges from $1 \mathrm{kHz}$ to $3 \mathrm{kHz}$ in $500 \mathrm{~Hz}$ steps. The shown configurations of frequency, amplitude and opening diameter are cutouts from the DoE, showing the results with the best ratio from standard deviation and mean powder mass flow. Preliminary tests had shown less sensitivity to smaller steps, like the frequencies used for copper. It has alternating positive and negative slopes like copper, but the median values alter less, whereas the standard deviation of the mass flow has higher fluctuations. The maximum calculated mass flow is $52.34 \mathrm{mg} / \mathrm{s}$, which is also caused by the resonant frequency of the setup. The last investigated powder material is vanadium. The conveyor curve of vanadium is shown in Fig. 8. The 


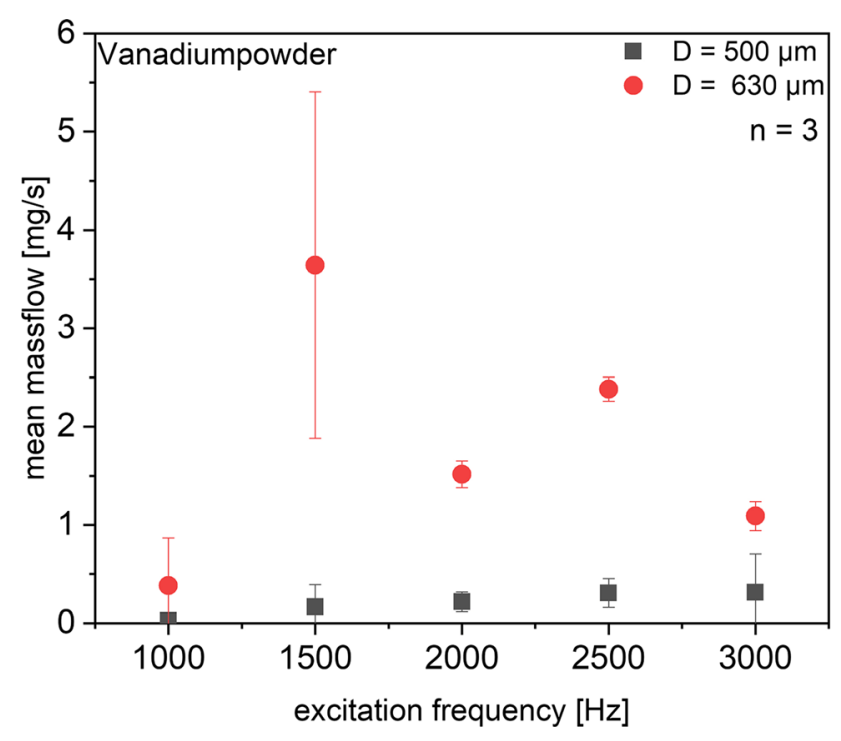

Fig. 8 Conveyor curve of vanadium powder with amplitude $=5 \mathrm{~V}$ and the opening diameters of $500 \mu \mathrm{m}$ and $630 \mu \mathrm{m}$ between $1 \mathrm{kHz}$ and $3 \mathrm{kHz}$

investigated frequencies and tube diameters are the same as for iron. Preliminary tests had shown controllable powder flow in the same area as for iron. For $1.5 \mathrm{kHz}$ and dispensing diameter of $630 \mu \mathrm{m}$ a significant increase in mass flow and standard deviation can be observed. A possible explanation for the difference in the preferable opening diameter is the size of the powder particles. As shown in Table 2, the copper powder, which works with a $110 \mu \mathrm{m}$ diameter, consists of smaller particles in comparison to iron and vanadium, which produce the highest mass flows with $500 \mu \mathrm{m}$ or $630 \mu \mathrm{m}$.

\subsection{Mass Flow Characterization of Polymer Powders}

The mass flow characteristics of the filled polymer systems are shown in Fig. 9. Three different tube diameters are used to define dependencies between the opening diameters and the generated mass flow. Generally, the mass flow increases with increasing tube diameter, as there is more place to flow. Using the smallest opening only very low mass flow can be detected. A tube diameter of $700 \mu \mathrm{m}$ leads to a defined mass flow stopping at $570 \mathrm{~Hz}$. Above that frequency range, no powder is excitated. Observing the composite with a filler grade of 5 vol.\%, Fig. 9a, a peak can be observed as with increasing frequency the mass flow rises until a maximum is reached. At that point, the system reaches its resonance frequency, where the most output at lowest energy input takes place and the system is excitated to vibration and adhesion forces are destructed. By using this tube diameter, a clear start-stop-effect of the powder output and therefore a stable process handling can be seen, whereby the intensity of the mass flow is dependent on the frequency. A higher tube diameter leads to an increased mass flow with a broad peak within the observed frequency range. At a higher filler content of 20 vol.\% glass fibers, Fig. 9b, the magnitude of order of the mass flow does not change significantly, but two critical frequencies, where dispensing starts to take place and where it ends, can be observed.

Fibers have a high aspect ratio, which leads to numerous fiber-fiber interactions during powder flow. A higher filler content results in decreased powder flowability and a higher vibrational excitation might be needed. A multiple of the particle size is needed as a tube diameter to achieve powder output due to the interparticle forces and interactions (Ref 34, p. 331). The experiments are conducted under ambient conditions, and the real PBF-LB/P process takes place at elevated temperatures, like $170{ }^{\circ} \mathrm{C}$. The flowability of the material at high temperatures will be different; nevertheless, it is of high importance to gain basic knowledge, primarily.

\subsection{Line Geometry Characterization}

The following section deals with the geometrical characterization of the deposited powder lines. The examined outcome is the line width. The line width determines the duration of the additional coating process with the powder dispensing system. The aim is to dispense only as much powder on the bed as the laser can melt in one scanning process, and the powder in the bed can be reused without the need of extensive purifying procedures. The configurations, which are presented, are again a part of the DoE. The chosen parameters have a ratio of standard deviation to line diameter which makes it plausible to test them on geometrical dispensing properties. The results will be discussed according to their usability in a powder bed. The aim is the determination of dispensing parameters which can be the base for the test system combined with movability in $\mathrm{x}$ - and $\mathrm{y}$-direction.

5.3.1 Metal Powders. For the line width test for copper two configurations with an opening diameter of $110 \mu \mathrm{m}$ and an amplitude of $10 \mathrm{~V}$ with two frequencies of $1600 \mathrm{~Hz}$ and 1800 $\mathrm{Hz}$ were used. Figure 9 shows the line diameter of the dispensed copper lines for the chosen configuration. There is a drop in line diameter and standard deviation for $1800 \mathrm{~Hz}$, while the line diameter is more continuous over the dispensing distance. The calculated mean powder flow per second values differ less. From the so far acquired data, there is no valid explanation for this trend and will be subject to future investigations. Nevertheless, the configuration $(D=110 \mu \mathrm{m}$, $\mathrm{A}=10 \mathrm{~V}$ and $\mathrm{f}=1800 \mathrm{~Hz}$ ) will be used for in situ tests of local modification of Ti6Al4V specimens.

The conducted deposition tests for iron consist of three parts. The first configuration was a tube diameter of $330 \mu \mathrm{m}$, an amplitude of $10 \mathrm{~V}$ and a frequency of $3000 \mathrm{~Hz}$. The second was a tube diameter of $500 \mu \mathrm{m}$, an amplitude of $5 \mathrm{~V}$ and a frequency of $2000 \mathrm{~Hz}$, while the third one was a tube diameter of $630 \mu \mathrm{m}$, an amplitude of $5 \mathrm{~V}$ and a frequency of $1500 \mathrm{~Hz}$. Figure 10 shows the same trend to better geometrical accuracy with higher frequency compared to lower ones. With $f=3 \mathrm{kHz}$, it shows the thinnest line with the least deviation. The configuration $(D=630 \mu \mathrm{m}, A=5 \mathrm{~V}$ and $f=3 \mathrm{kHz})$ is another candidate for in situ tests in PBF-LB/M of Ti6Al4V.

The last investigated powder line width was vanadium. Again, three configurations were used. The first was a tube diameter of $330 \mu \mathrm{m}$, an amplitude of $10 \mathrm{~V}$ and a frequency of $1500 \mathrm{~Hz}$. The second was a tube diameter of $500 \mu \mathrm{m}$, an amplitude of $10 \mathrm{~V}$ and a frequency of $2000 \mathrm{~Hz}$. The third was a tube diameter of $630 \mu \mathrm{m}$, an amplitude of $5 \mathrm{~V}$ and a frequency of $2000 \mathrm{~Hz}$. Vanadium shows the most remarkable deposition behavior. In contrast to the homogeneous powder lines from copper and iron, the vanadium leaves the tube in pellets. A possible explanation is that the non-spherical powder particles pack in the area of the tube opening. When they reach a critical pack density, a small amount forms a pellet, which then 

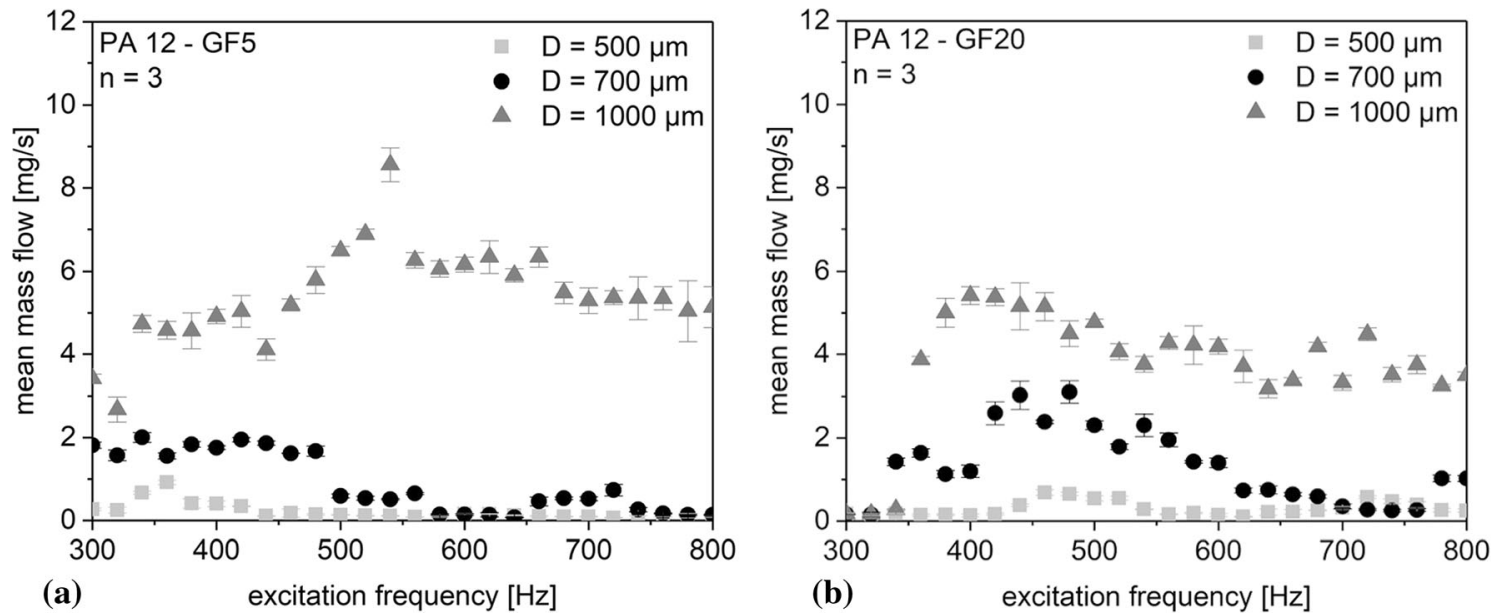

Fig. 9 Mass flow characteristics of glass fiber-filled polymer systems. (a) PA 12 -GF5, (b) PA 12 - GF20

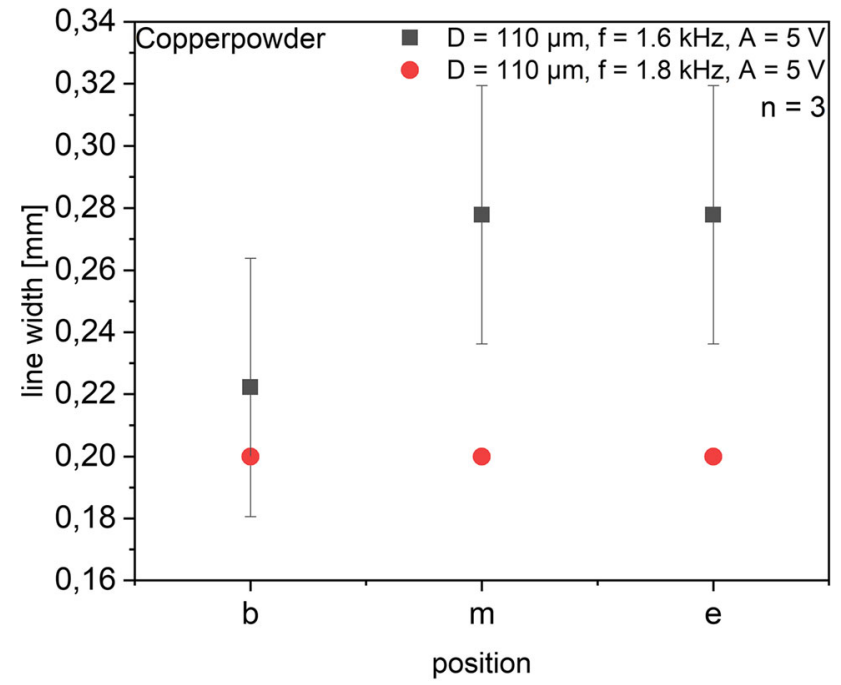

Fig. 10 Line width of copper on glass slide for b(egin), m(iddle), e(nd)

behaves like a single particle. The pellet is again broken up after contact with the microscope slide. Therefore, the characterization of the vanadium lines is to be seen as approximately since there are no continuous lines. Figure 11 shows the values for line width during the dispensing of vanadium powder. On the contrary to copper and iron, vanadium has no clear preferable configuration for accuracy. For vanadium, a special dispensing trajectory system seems necessary to ensure a feasible distribution on the powder bed. This could be an advantage since Karg et al. (Ref 8 ) propose a non-covering but spotty distribution of powder for in situ alloying. The broader line width distribution can also be interesting in hatching studies for dispensing trajectory development. This could increase the area per time which can be in situ modified.

5.3.2 Polymer Powders. The geometry of the excitated powder line for polymer processes with the frequencies with maximum powder output and the suitable tube diameter of 700 $\mu \mathrm{m}$ is evaluated for both powder mixtures at three different line positions (start, mid and end) in Fig. 12a, b. A mean line width of around $1.5 \mathrm{~mm}$ to $2.0 \mathrm{~mm}$ is generated, which has to be

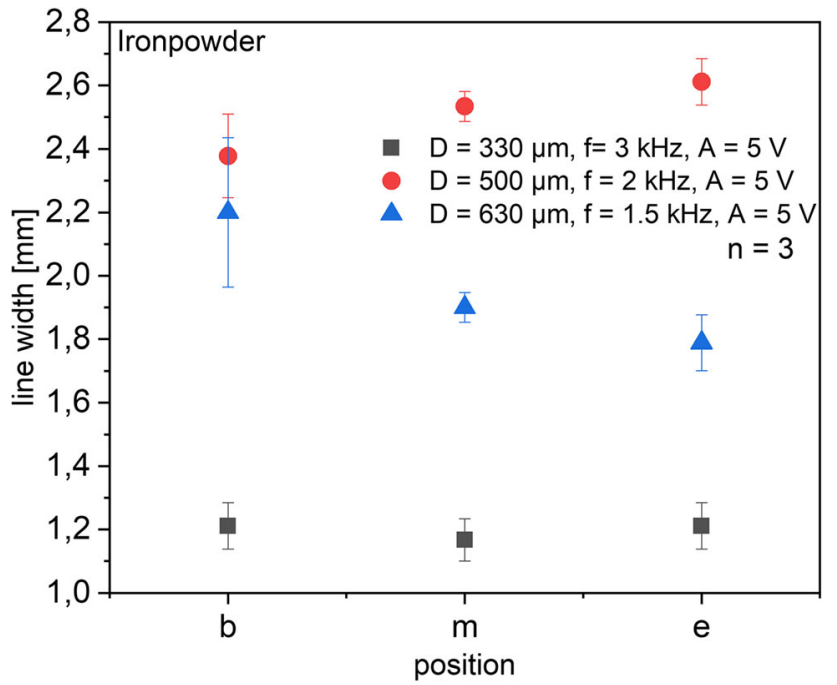

Fig. 11 Line width of iron on glass slide b(egin), m(iddle), e(nd)

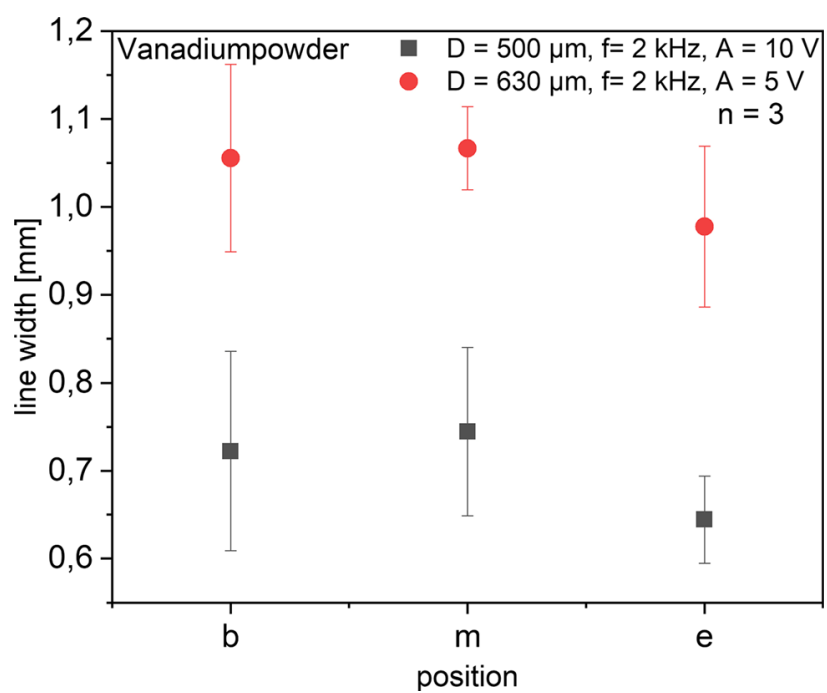

Fig. 12 Line width of vanadium on glass slide b(egin), m(iddle), e(nd) 
considered for designing locally filled polymer parts. A higher line width can be observed at the end of the line as no spontaneous and direct stopping of the powder deposition takes place when end position is reached. For the PA 12-GF 20 mixture, Fig. 12 b, this effect can be reduced as the flowability is lower than for the PA 12-GF5 powder, but it flows in a less diffuse way, which can be also seen by the reduced standard deviation of the line width. By the variation of the distance between tube and powder bed surface, the dimensions of the line width can be adjusted. A higher distance between tube opening and surface would lead to a more diffuse powder discharge and therefore an increased width. The parameters have then to be adjusted according to the requirements.

5.3.3 Powder Bed Surrogate Line Deposition. After the geometry of the dispensed line was investigated, the next aim was to characterize the line width in combination with a powder bed below it. Therefore, a powder bed surrogate was filled with $20 \mathrm{~g}$ of Ti6Al4V to simulate process conditions. After the layer of matrix powder was deposited, the alloy powders were dispensed, and the line width was measured the same way as before. The contact mechanics should be analyzed. As Fig. 13 shows, the powder does not sink into the powder bed as deep as needed for a homogeneous layer height. The difference in powder height over the area of one layer leads to an unstable process behavior. For future tests, this must be taken into account. Figure 13a and b also shows the line width of a deposited iron and vanadium line on the powder bed.

The excitated filled polymer powder lines are depicted in Fig. 14. For a better contrast black polyamide 12 powder (PA 2202) is used as the matrix. Due to the inhomogenity of the powder line, an exact measurement of the line width is complex. Nevertheless, it can be observed that the filled powder with a higher filler content of 20 vol. $\%$ tends to slimmer lines as the decreased flowability with increasing filler content leads to less diffusivity during excitation (Fig. 15).

The results are essential for the evaluation of graded part properties. For defined local mechanical properties, the mass flow and geometry of the excitated filler powder have to be known so that an exact adjustment of the required properties can be made. Moreover, the mass flow is important for the layout of the feed speed of the linear axes for the nozzle in the $\mathrm{x}-\mathrm{y}$ mechanism, which is implemented in the machine, respectively, as a higher or lower speed is another parameter

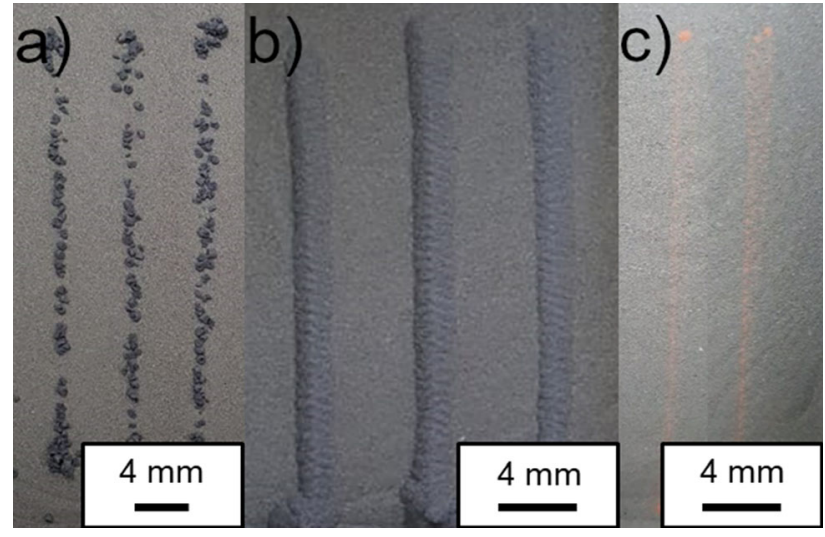

Fig. 14 Powder lines on powder bed surrogate (a) vanadium and (b) iron (c) copper

to be considered. Exemplarily, a higher speed would lead to slimmer and thinner powder lines.

\subsection{Comparison of Metal and Polymer Systems}

Comparing the polymer-based material systems and metal systems, different dispensing parameters are necessary. Firstly, the broad particle size distribution of the filler systems, consisting of PA 12 and short glass fibers, requires a higher tube diameter. In contrast, the required excitation frequency is lower for polymers systems compared to the investigated metals due to a lower density. The higher inter-particle forces like electrostatic forces, which exist for polymer systems, decrease the flow additionally (Ref 5, p. 243, Ref 35, p. 141). The higher density of the metal powders builds up increased hydrostatic pressure, which leads to higher mass flow rates in comparison to the polymer powders. The self-induced higher pressure (copper-induced pressure is near to nine times the pressure of PA 12, according to the difference in density) can also be the reason for higher necessary frequencies for flow in the metal powder. The high density leads to high compression, while the cross section of the glass tube is decreasing. More energy in form of higher frequency is needed to break the forming bulk. Vanadium forms pellets, and as a result, its dispensing behavior is more similar to the polymer powders.


Fig. 13 Line widths of the excitated powder lines. (a) PA 12 - GF5, (b) PA 12 - GF20 

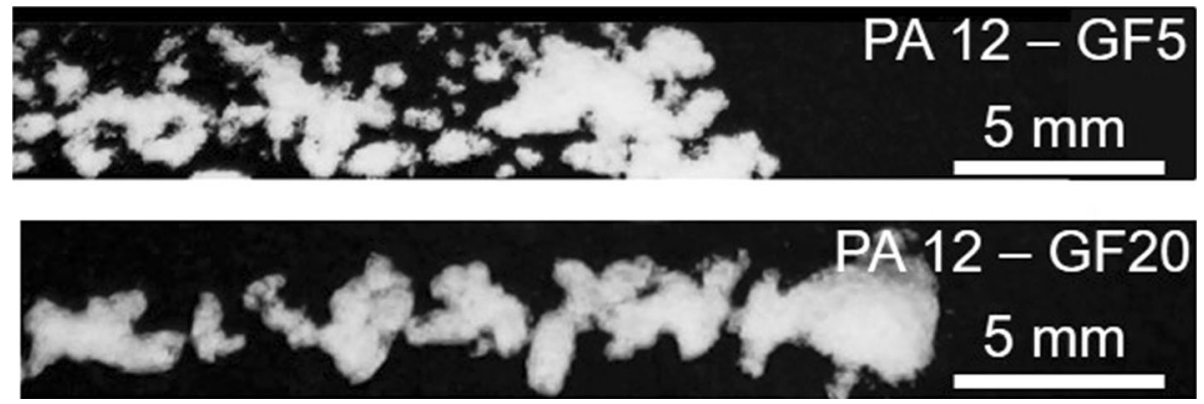

Fig. 15 Powder lines on powder bed surrogate with an amplitude $=5 \mathrm{~V}$, frequency $=500 \mathrm{~V}$ and opening diameter of $700 \mu \mathrm{m}$

The literature indicates that a maximum mass flow can be detected when the system reaches its resonance frequency or higher modes (Ref 34, p. 461, Ref 36). The polymer powders need bigger diameters for powder flow in comparison to metal powders, but the frequencies, which produce a similar mass flow to metals, are smaller. Polymer flow starts around $300 \mathrm{~Hz}$, metal flow starts at $1000 \mathrm{~Hz}$, even for the same diameter of 500 $\mu \mathrm{m}$. This could be linked to the different stress-strain behavior of the two material groups. Jenike describes the material flow theoretically with a yield function, which depends on stress and angle of friction (Ref 37, p. 230). Considering the stress-strain behavior of metals and polymers, the critical stress for flowing for polymers is less considering their lower Young's modulus. This could be the explanation why higher energy in form of vibration frequency is needed for flow in the metal powders. The suitable tube diameter is dependent on particle size distribution and flowability as well as the materials itself concerning inter-particle forces (Ref 38, p. 239]. Therefore, the necessary dispensing parameters are dependent on the individual material system.

For both systems, the discharged materials have to be analyzed in the part itself concerning bonding to the matrix material after melting, the process order, i.e., powder discharge before or after melting, and local mechanical properties, perspectively.

\section{Conclusion and Outlook}

The goal of this study was to evaluate local alloy or filler deposition for PBF-LB for graded part properties and to gain transferable basic knowledge on the deposition behavior of polymer and metal material classes in micropowder feeding to derive process strategies for the local powder and part modification during the real process. Hereby, the frequency and tube diameters, which have the most significant effect on the mass flow, are varied. On the one hand, metal alloy elements for PBF-LB/M and on the other hands glass fiber filler systems for PBF-LB/P are analyzed, and both additives show a dependency of the excitation frequency and dispensing tube diameter. The results are summarized below.

- The factor with the highest impact on mass flow is the tube opening diameter. Therefore, the impact of frequency and amplitude must be characterized in dependency of the opening diameter.

- Frequency and amplitude create a complex dynamic. It is possible to control the mass flow with variation of just one of the two parameters, but the characterization of both in interaction is preferable.

- The precision of the line geometry decreases with increasing particle size and mass flow. This has to be considered within the real process, where the dispensing parameters have to be adjusted to achieve the specified additive concentration and required precision.

- To determine the usability of a parameter combination, it is necessary to investigate mass flow and line geometry. If the deposition is not stable, it is not possible to create a homogeneous additive layer or to control the material combination.

As the results have shown, the presented system and approach are suitable for spatially defined addition of powder particles in a powder bed. Still there are some challenges linked with this approach. On the one hand, the mass flow and the geometrical specifications of the dispensed powder can be reliably adjusted. On the other sides, the height of the deposited lines has to be considered for implementation in an $\mathrm{PBF}-\mathrm{LB} / \mathrm{M} / \mathrm{P}$ process. One possible solution is the integration of an additional coating mechanism. Another is the dispensing strategy itself. Two exemplary options would be the deposition before the coating process or adapted process parameters to compensate the higher layer height. Another approach that will be subject of future investigation is the variation of the distance between dispensing tube and the powder bed. The concentration of particles per volume unit decreases with increasing distance of the tube. It should be possible to deposit wider lines with a lower addition of filler and alloying elements. The possibility of locally graded part properties warrants further investigation.

Perspectively, the dispenser unit will be implemented into the PBF-LB/M/P machines to generate locally graded part properties during the real process. Afterward, the part properties will be analyzed and correlated with the spatial filler or alloying concentration or dispensing strategy, respectively.

\section{Acknowledgments}

This study has been funded by the Deutsche Forschungsgemeinschaft (DFG, German Research Foundation) - Project-ID 61375930 - SFB 814, Subproject B5 and A6. The financial support is gratefully acknowledged. Support from the Erlangen Graduate School in Advanced Optical Technologies (SAOT) in the framework of DFG's excellence initiative is also gratefully acknowledged.' 


\section{Open Access}

This article is licensed under a Creative Commons Attribution 4.0 International License, which permits use, sharing, adaptation, distribution and reproduction in any medium or format, as long as you give appropriate credit to the original author(s) and the source, provide a link to the Creative Commons licence, and indicate if changes were made. The images or other third party material in this article are included in the article's Creative Commons licence, unless indicated otherwise in a credit line to the material. If material is not included in the article's Creative Commons licence and your intended use is not permitted by statutory regulation or exceeds the permitted use, you will need to obtain permission directly from the copyright holder. To view a copy of this licence, visit http://creativecommons.org/licenses/by/4.0/.

\section{Funding}

Open Access funding enabled and organized by Projekt DEAL.

\section{References}

1. J.P. Kruth, Material Incress Manufacturing by Rapid Prototyping Techniques, CIRP Ann., 1991, 40(2), p 603-614. https://doi.org/10. 1016/S0007-8506(07)61136-6

2. T. Wohlers, R. I. Campbell, O. Diegel, R. Huff, and J. Kowen, Wohlers report 2020: 3D printing and additive manufacturing state of the industry. Fort Collins, Colo.: Wohlers Associates, 2020

3. Additive Fertigung - Grundlagen -: Terminologie (ISO/ASTM DIS 52900:2018), 52900

4. W.E. Frazier, Metal Additive Manufacturing: A Review, J. Mater. Eng. Perform, 2014, 23(6), p 1917-1928. https://doi.org/10.1007/s11665014-0958-Z

5. Y. Jiang, S. Matsusaka, H. Masuda and Y. Qian, Development of Measurement System for Powder Flowability Based on Vibrating Capillary Method, Powder Technol., 2009, 188(3), p 242-247. https://d oi.org/10.1016/j.powtec.2008.05.003

6. A.T. Silvestri, S. Amirabdollahian, M. Perini, P. Bosetti and A. Squillace, Direct Laser Deposition for Tailored Structure, ESAFORM, 2021 https://doi.org/10.25518/esaform21.4124

7. O. Hentschel et al., Processing of AISI H11 Tool Steel Powder Modified with Carbon Black Nanoparticles for the Additive Manufacturing of Forging Tools with Tailored Mechanical Properties by Means of Laser Metal Deposition (LMD), Metals, 2018, 8(9), p 659. https://d oi.org/10.3390/met8090659

8. M.C.H. Karg et al., Laser Alloying Advantages by Dry Coating Metallic Powder Mixtures with SiOx Nanoparticles, Nanomaterials (Basel, Switzerland), 2018 https://doi.org/10.3390/nano8100862

9. A. Sommereyns, T. Hupfeld, B. Gökce, S. Barcikowski and M. Schmidt, Evaluation of Essential Powder Properties Through Complementary Particle Size Analysis Methods for Laser Powder Bed Fusion of Polymers, Procedia CIRP, 2020, 94, p 116-121. https://doi.org/10. 1016/j.procir.2020.09.023

10. A.E. Hassanin, F. Scherillo, U. Prisco, R. Sansone and A. Astarita, Selective Laser Melting of Cu-inconel 718 Powder Mixtures, J. Manuf. Process., 2020, 59, p 679-689. https://doi.org/10.1016/j.jmapro.2020. 10.039

11. L. Lanzl, K. Wudy, S. Greiner and D. Drummer, Selective Laser Sintering of Copper filled Polyamide 12: Characterization of Powder Properties and Process Behavior, Polym. Compos., 2019, 40(5), p 1801-1809. https://doi.org/10.1002/pc.24940

12. H. Chen, Q. Wei, Y. Zhang, F. Chen, Y. Shi and W. Yan, PowderSpreading Mechanisms in Powder-Bed-Based Additive Manufacturing: Experiments and Computational Modeling, Acta Mater, 2019, 179, p 158-171. https://doi.org/10.1016/j.actamat.2019.08.030

13. H. Chen, Y. Chen, Y. Liu, Q. Wei, Y. Shi and W. Yan, Packing Quality of Powder Layer During Counter-Rolling-Type Powder Spreading Process in Additive Manufacturing, Int. J. Mach. Tools Manuf, 2020, 153, 103553. https://doi.org/10.1016/j.ijmachtools.2020.103553
14. H. Chen, W. Zhu, H. Tang and W. Yan, Oriented Structure of Short Fiber Reinforced Polymer Composites Processed by Selective Laser Sintering: The Role of Powder-Spreading Process, Int. J. Mach. Tools Manuf, 2021, 163, 103703. https://doi.org/10.1016/j.ijmachtools.2021. 103703

15. T. Heckner, M. Seitz, S.R. Raisch, G. Huelder and P. Middendorf, Selective Laser Sintering of PA6: Effect of Powder Recoating on Fibre Orientation, J. Compos. Sci., 2020, 4(3), p 108. https://doi.org/10.3390/ jes4030108

16. T. Stichel, T. Laumer, P. Amend, S. Roth, and P. Wittmann, Eds., Selective deposition of polymer powder by vibrating nozzles for laser beam melting, 2015

17. C. Anstaett and C. Seidel, Multi-Material Processing, Laser Tech. J., 2016, 13(4), p 28-31. https://doi.org/10.1002/latj.201600027

18. Aconity3d, AconityMIDI+. [Online]. Available: https://aconity3d.com/ products/aconitymidi-2/ (accessed: Oct. 8 2020)

19. F. Huber, T. Papke, C. Scheitler, L. Hanrieder, M. Merklein and M. Schmidt, In Situ Formation of a Metastable $\beta$-Ti Alloy by Laser Powder Bed Fusion (L-PBF) of Vanadium and Iron Modified Ti-6Al4V, Metals, 2018, 8(12), p 1067. https://doi.org/10.3390/met8121067

20. A.T. Silvestri, S. Foglia, R. Borrelli, S. Franchitti, C. Pirozzi and A. Astarita, Electron Beam Melting of Ti6A14V: Role of the Process Parameters Under the Same Energy Density, J. Manuf. Process., 2020, 60, p 162-179. https://doi.org/10.1016/j.jmapro.2020.10.065

21. U. Prisco, A. Astarita, A. El Hassanin and S. Franchitti, Influence of Processing Parameters on Microstructure and Roughness of Electron Beam Melted Ti-6Al-4V Titanium Alloy, Mater. Manuf. Processes, 2019, 34(15), p 1753-1760. https://doi.org/10.1080/10426914.2019.1 683576

22. C.Y. Yap et al., Review of Selective Laser Melting: Materials and Applications, Appl. Phys. Rev., 2015, 2(4), p 41101. https://doi.org/10. $1063 / 1.4935926$

23. S. Liu and Y.C. Shin, Additive Manufacturing of Ti6Al4V Alloy: A Review, Mater. Des., 2019, 164, 107552. https://doi.org/10.1016/j.ma tdes.2018.107552

24. C. Cui, B. Hu, L. Zhao and S. Liu, Titanium Alloy Production Technology, Market Prospects and Industry Development, Mater. Des., 2011, 32(3), p 1684-1691. https://doi.org/10.1016/j.matdes.2010.09.0 11

25. M. J. Donachie, Titanium: A technical guide, 2nd ed. Materials Park, Ohio: ASM International, 2010

26. V. Chastand, A. Tezenas, Y. Cadoret, P. Quaegebeur, W. Maia and E. Charkaluk, Fatigue Characterization of Titanium Ti-6Al-4V Samples Produced by Additive Manufacturing, Procedia Struct. Integ., 2016, 2, p 3168-3176. https://doi.org/10.1016/J.PROSTR.2016.06.395

27. H. Masuo et al., Influence of Defects, Surface Roughness and HIP on the Fatigue Strength of Ti-6Al-4V Manufactured by Additive Manufacturing, Int. J. Fatigue, 2018, 117, p 163-179. https://doi.org/10. 1016/j.ijfatigue.2018.07.020

28. F. Huber et al., Customized Exposure Strategies for Manufacturing Hybrid Parts by Combining Laser Beam Melting and Sheet Metal Forming, J. Laser Appl., 2019, 31(2), p 22318. https://doi.org/10.2351/ 1.5096115

29. M. Rasch et al., Grain Structure Evolution of Al-Cu Alloys in Powder Bed Fusion with Laser Beam for Excellent Mechanical Properties, Materials (Basel, Switzerland), 2019, 13(1), p 82. https://doi.org/10. 3390/ma13010082

30. K. Wudy, L. Lanzl and D. Drummer, Selective Laser Sintering of Filled Polymer Systems: Bulk Properties and Laser Beam Material Interaction, Phys. Procedia, 2016, 83, p 991-1002. https://doi.org/10.1016/j. phpro.2016.08.104

31. A. Mazzoli, G. Moriconi and M.G. Pauri, Characterization of an Aluminum-Filled Polyamide Powder for Applications in Selective Laser SINTERING, Mater. Des., 2007, 28(3), p 993-1000. https://doi. org/10.1016/j.matdes.2005.11.021

32. SLM Solutions Group AG: SLM®500. [Online]. Available: https:// www.slm-solutions.com/en/products/machines/slm500/ (accessed: Oct. 2 2020)

33. L. Lanzl, K. Wudy and D. Drummer, The Effect of Short Glass Fibers on the Process Behavior of Polyamide 12 During Selective Laser Beam Melting, Polym. Testing, 2020, 83, 106313. https://doi.org/10.1016/j. polymertesting.2019.106313 
34. D. Schulze, Pulver und Schüttgüter: Fließeigenschaften und Handhabung, 3rd ed. Berlin: Springer Vieweg, 2014. [Online]. Available: h ttp://gbv.eblib.com/patron/FullRecord.aspx?p=1967825

35. S. Matsusaka, K. Yamamoto and H. Masuda, Micro-Feeding of a Fine Powder Using a Vibrating Capillary Tube, Adv. Powder Technol., 1996, 7(2), p 141-151. https://doi.org/10.1016/S0921-8831(08)60509-9

36. Y. Jiang, S. Matsusaka, H. Masuda and T. Yokoyama, Evaluation of Flowability of Composite Particles and Powder Mixtures by a Vibrating Capillary Method, J. Chem. Eng. Japan / JCEJ, 2006, 39(1), p 14-21. https://doi.org/10.1252/jcej.39.14

37. A.W. Jenike, A Theory of Flow of Particulate Solids in Converging and Diverging Channels Based on a Conical Yield Function, Powder
Technol., 1987, 50(3), p 229-236. https://doi.org/10.1016/0032-5910( 87) $80068-2$

38. A.W. Jenike, Quantitative Design of Mass-Flow Bins, Powder Technol., 1967, 1(4), p 237-244. https://doi.org/10.1016/0032-5910(6 7) $80042-1$

Publisher's Note Springer Nature remains neutral with regard to jurisdictional claims in published maps and institutional affiliations. 